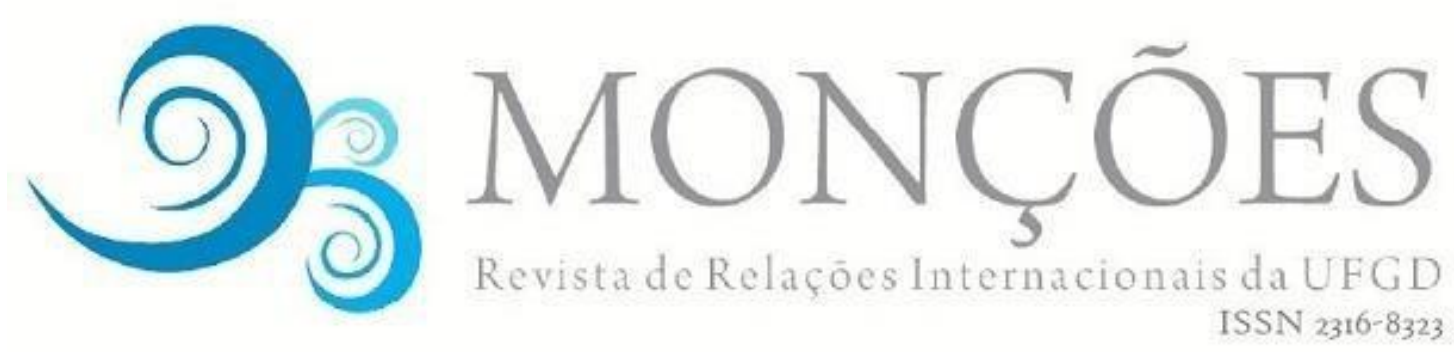

\title{
VISÕES INDÍGENAS DESAFIANDO O GLOBAL: MULHERES KICHWA PLURALIZANDO A SOBERANIA*
}

MANUELA LAVINAS PICQ

Manuela Lavinas Picq, acadêmica e jornalista, é professora de Relações Internacionais na Universidade de São Francisco de Quito (USFQ), Equador, e professora visitante no Amherst College, Massachusetts. Ela é co-editora de Sexualities in World Politics e Queering Narratives of Modernity.

TRADUTORA

XAMAN MINILLO KORAI

Professora do Departamento de Relações Internacionais da Universidade Federal da Paraíba (UFPB), graduada (2008) e mestra (2011) em Relações Internacionais pela Universidade de Brasília

REVISOR DA TRADUÇÃO JOÃO NACKLE URT

Professor da Faculdade de Direito e Relações Internacionais da Universidade Federal da Grande Dourados (UFGD) e Doutor em Relações Internacionais pela Universidade de Brasília

\section{Introdução}

A soberania estatal parece estar fora de moda. Teóricos políticos preeminentes reiteraram repetidamente a necessidade de ir além do estadonação: Arjun Appadurai (1993) nos pede para "pensar em nós mesmos para além da nação"; Partha Chatterjee (1993) nos diz para olhar para dentro dela; e Dipesh Chakrabarty (2000) provincializou a Europa, com seu sistema de estados-nação, como um guia inadequado para possibilidades políticas. Estudiosos abordaram a ética da pós-soberania (SHAPIRO, 1994) e agora buscam novas formas de pensar o estado (MIGDAL, 2009). Lenta, mas seguramente, tentativas de se libertar da camisa de força histórica do estado-

\footnotetext{
* A referência do texto original é: PICQ, Manuela L. "Indigenous Worlding: Kichwa women pluralizing sovereignty". In: Arlene B. Tickner e David L. Blaney (Eds.), Claiming the International. New York: Routledge, 2013, p. 121-140.
} 
nação como forma esperada de organização política infiltram-se nas Relações Internacionais (RI), uma disciplina que canonizou a soberania vestfaliana como um fato consumado. Abrir nossos imaginários para padrões não-dominantes de produção e conhecimento nos força a perguntar o que seria uma política mundial emancipada do estado. Se formos silenciar a obsessão das RI com a soberania, precisamos complementar conceituações com práxis. Além de gramáticas pósnacionais, precisamos identificar possibilidades concretas do que pode existir para além e dentro do estado.

A indigenidade é talvez o mais "além" do estado que podemos ir. Escapando de concepções estatistas de fronteiras, enraizadas em modos de vivência não-ocidentais e implicando uma legitimidade política que precede o estado, a indigenidade é um local estratégico a partir do qual se pode repensar a soberania. A política indígena oferece intuições radicalmente diferentes sobre o internacional, pois envolve formas de governança constituídas fora, que, em grande medida precedem o estado moderno. E como não há como divorciar teoria de um ponto de vista no tempo e espaço (COX, 1986), a indigenidade constitui uma posicionalidade única para contestar histórias hegemônicas, com cosmologias políticas que desnaturalizam o estado como lócus único do político (BEIER, 2005). Mais especificamente, práticas indígenas de autoridade - plurais, compartilhadas e não limitadas pelos estados - exemplificam como "distribuir" a soberania convencional, repercutindo esforços de emancipar a política mundial dos grilhões das práticas políticas eurocêntricas (SHILLIAM, 2010).

Entendimentos dominantes de estatalidade estão crescentemente sob ataque. Fronteiras disciplinares são contestadas por vozes da periferia (TICKNER; BLANEY, 2012) em termos metodológicos (JACKSON, 2011) e contando histórias como uma forma de produção de conhecimento (INAYATULLAH, 2011). A crítica feminista, contestando epistemologias de RI, (TICKNER, 1997) foi complementada por perspectivas pós-coloniais buscando desenrolar histórias silenciadas, enquanto projetos políticos pós-racistas intensificaram a contestação do eurocentrismo do campo (HOBSON, 2007; VITALIS, 2010). Críticos retratam o internacional como mais heterogêneo que o senso comum reconhece, mas poucos parecem envolver perspectivas indígenas para incentivar a criatividade política. 
Percebida como um particularismo local desconectado do internacional, ou muito vernacular para ser digna de categorizações universais, a indigenidade continua a ser majoritariamente negligenciada pelos pesquisadores de RI. Povos indígenas parecem ser "relíquias", mais relevante para antropólogos que estudiosos dapolítica global. Depois de serem deixados de fora da história por processos seletivos de construção de memória (O'BRIEN, 2010), os povos indígenas foram silenciados na modernidade política (BEIER, 2009). Imaginários persistentes deste tipo destoam da sofisticação das práxis políticas indígenas, indicando a dose de colonialismo ainda embutida na disciplina (SHAW, 2008). Ao mesmo tempo em que têm colhido grãos milenares e falado línguas précolombianas, os povos indígenas das Américas têm articulado seus interesses nos domínios internacionais há muito tempo. Lutas indígenas são fundamentalmente globais, mesmo se tratadas como irremediavelmente apolíticas e implicitamente localizadas nas fronteiras da racionalidade política.

Este capítulo argumenta que a indigenidade é um lócus valioso para o pensamento crítico. A experiência política dos povos indígenas, e especialmente das mulheres indígenas, é crucial para repensar o mundo da política. Também busca visibilizar o dinamismo internacional da política indígena e enfatiza seus esforços para contrapor o estadocentrismo. Seguindo a sugestão de Chatterjee (1993) de olhar para dentro da nação, eu integro abordagens etnográficas a um ponto de vista feminista para mostrar como mulheres indígenas moldam o internacional. Sustento meu argumento com uma análise de um estudo de caso de mulheres indígenas no Equador. Localizando sua política na intersecção de direitos coletivos indígenas e direitos internacionais das mulheres, as mulheres kichwa articulam política indígena, o estado-nação e normas internacionais de modos que deslocam formas convencionais de autoridade legal. Sua busca por justiça é profundamente imbricada com a política global e resulta em práticas de soberania dispostas em múltiplas camadas que se sobrepõem umas às outras. No geral, esta análise postula a indigenidade como uma categoria de análise significativa, ainda que negligenciada, para pensar as RI diferentemente.

No que se segue, proponho primeiramente a indigenidade como uma perspectiva estratégica, que move o internacional para além do estadocentrismo. Em seguida, volto-me ao uso que as mulheres indígenas fazem da política global 
no Equador, derrubando entendimentos aceitos do que constitui o internacional, onde ele se localiza e quem são seus atores legítimos. Embora percebidas como periféricas - e até mesmo externas - às $\mathrm{Rl}$, as mulheres indígenas estão realocando a soberania legal para além do estado-nação. Finalmente, analiso a significância das formas indígenas de soberania para identificar roteiros alternativos na política global. A triangulação de autoridade judicial entre direitos indígena, doméstico e internacional desloca a soberania legal não a partir de cima, como na União Europeia (UE), mas a partir de geografias alternativas dentro do estado.

\section{Por que a indigenidade importa}

\section{Formas de ver o internacional}

A indigenidade oferece potenciais insightspara pensar diferentemente sobre o internacional, para romper com silêncios disciplinares e para ir além do estadocentrismo. É uma categoria de análise valiosa porque resgata histórias consideradas irrelevantes e invisibilizadas nas narrativas hegemônicas da política global. Em primeiro lugar, a indigenidade expande formas de ver. Narrativas hegemônicas contemporâneas acerca do estado, tais como as lentes coloniais do passado, parecem particularmente inaptas em ver qualquer coisa além daquilo que seja semelhante a si próprio. A historiadora de arte Carolyn Dean descreve a consternação dos colonizadores espanhóis encontrando ídolos andinos "feios" (DEAN, 2010, p.11). Os espanhóis buscavam o sagrado em formas de "arte" familiares, esteticamente agradáveis de acordo com seus padrões, em lugar do panorama andino. Eles eram, de forma similar, incapazes de apreender as perspectivas incas acerca das pedras - animadas, poderosas e conscientes. Tal inabilidade em acessar o significado inca ecoa a inabilidade colonial mais ampla de ler pontos de vista alternativos. Naquela época, como agora, a capacidade de reconhecer outras formas de saber está entrelaçada com formulações do eu político. Vanita Seth (2010) analisa a dificuldade europeia de ver (e representar) a diferença como advinda de uma inabilidade mais ampla de converter em uma linguagem política familiar o Novo Mundo encontrado. 
Ainda hoje, parte da inabilidade em explicar dinâmicas indígenas na política global advém de sua alteridade. A indigenidade continua a resumir o nãocientífico e não-europeu, marginalizada como não confiável e sistematicamente excluída de processos legítimos de produção de conhecimento. Transplantando as noções dessa autora para leituras contemporâneas de política global, argumento que a indigenidade é uma ferramenta necessária para reconhecer a diversidade de configurações políticas diferentes do estadocentrismo ocidental. Ou, como Seth coloca, "é difícil falar a língua da alteridade quando o outro é virtualmente ausente do discurso do eu" (SETH, 2010, p.38). Mais crucialmente, manter invisíveis as histórias indígenas permite que omissões do passado se tornem as fundações de narrativas "científicas" (TROUILLOT, 1995). Então a invenção do indígena como selvagem persiste hoje em entendimentos implícitos que situam a indigenidade fora da "política de verdade". Pensar a partir de localizações tão marginais permite que tais silêncios sejam rompidos.

Dinâmicas similares são observáveis com relação a gênero e raça. A crítica feminista foi inovadora ao introduzir a ideia de posicionalidade nas relações internacionais. Ela expandiu entendimentos convencionais do que constitui o internacional, conceituando, por exemplo, o estupro como arma de guerra e definindo a masculinidade como uma questão de política externa (ENLOE, 2005). Mostrando como o gênero importa, o olhar feminista mudou o que a disciplina vê e novas metodologias de pesquisa abriram caminhos para pensar diferentemente (ACKERLY; STERN; TRUE, 2006). A posicionalidade permitiu ver outras invisibilidades, como os traços racistas das RI (TICKNER, 2010). Pesquisadores começaram a examinar o impacto do racismo sobre assuntos internacionais e denunciaram os pressupostos racistas que informam os construtos teóricos atuais da maior parte das teorias de RI (HENDERSON, 2013; HOBSON, 2007). Estas abordagens explicam, por exemplo, como incapacidades passadas de apreender a Revolução Haitiana (1791-1804), mesmo por seus contemporâneos (BUCK-MORSS, 2009), conspiram com silêncios atuais para manter a escravidão invisível - ou insignificante - nas narrativas convencionais de RI. Assim como metodologias feministas produziram novas formas de conhecimento, envolver formas indígenas de investigação (SMITH, 1999) contribuiu com camadas de complexidade para reformular e 
reparar nossas concepções da política global. Pesquisadores indígenas assumem o desafio de situar o eu além do gênero, atravessando paradigmas culturais por meio de pesquisa comunitária e aplicando a ética como metodologia (KOVACH, 2010). Validar a narração e a rememoração de estórias como formas de conhecimento, por exemplo, permite que histórias alternativas poderosas emerjam (MALLON, 2011). Se o nascimento das RI é uma história sobre império na qual fronteiras raciais importavam mais do que as territoriais, como alega Robert Vitalis (2010, p. 910), então é mais urgente ainda aplicar categorias como indigenidade para revisitar conceitos fundacionais com outros olhos.

De fato, povos indígenas nunca "desapareceram" como sugerem discursos perniciosos, embora duradouros, sobre a formação dos estados; nem são minorias folclóricas situadas nas margens (DEN OUDEN, 2005). Eles têm promovido ativamente lutas contra o estado colonial. No entanto, poucos pesquisadores de RI parecem estar interessados em articular o impacto de lutas indígenas na política global. Karena Shaw (2008) argumenta que esta marginalização conceitual deve-se, em parte, à colonialidade de uma disciplina que ainda considera ontologias indígenas objetos "inapropriados" de análise ou de política. Para J. Marshall Beier (2009), a política indígena não é uma história não-contada;é uma história não-ouvida. Histórias de mulheres indígenas são ainda menos ouvidas, a despeito de sua mobilização estratégica por políticas interseccionais em busca de direitos individuais das mulheres e direitos coletivos indígenas (PARISI; CORNTASSEL, 2007; BARKER, 2006).

Enquanto pesquisadores argumentam que o modelo moderno de soberania não vai funcionar para os povos indígenas, suas dinâmicas diplomacias são significativas para as RI precisamente por se diferenciarem de práticas ocidentais e estadocêntricas. É exatamente por que as formas indígenas de governança transcenderam o estadocentrismo que eles conseguem abstrair a soberania de suas limitações vestfalianas. Filosofias indígenas fornecem formas não-ocidentais de investigação para analisar a política mundial. Karen Smith (2012), por exemplo, utiliza o conceito sul-africano de ubuntu para complementar a estrutura global de direitos humanos. Enquanto pesquisadores individualmente deram contribuições pioneiras para ampliar o que constitui o 
internacional, ainda falta à disciplina um envolvimento teórico com a indigenidade enquanto categoria útil para a análise da política global.

Ainda assim, pesquisadores de fora das $\mathrm{Rl}$ aproveitaram as experiências indígenas para repensar a política estatal de formas fundamentais. Nos Andes, povos indígenas se auto-organizam na luta diária para se adaptarem às realidades locais e às forças externas de maneira independente do estado. Rudi Colloredo-Mansfeld (2009, p.17) refere-se a estas dinâmicas organizacionais indígenas como "artes de governo nativas". James C. Scott (2009), em seu agora famoso estudo, conta como os povos de Zomia deliberadamente mantiveram-se sem estado; segundo o autor, autodeterminação é a arte de não ser governado. Para pesquisadores de estudos nativos, por sua vez, o estado-nação é apenas uma geografia política entre muitas outras (BIOLSI, p.2005), e a noção de indigenidade como um "terceiro espaço de soberania" aponta para representações não-bináriasda vida política (BRUYNEEL, 2007). Abordagens indígenas permitem explicar variações nas práticas de autoridade, notadamente formas modulares ou compartilhadas de soberania. Podemos, então, reconhecer (e imaginar) rearranjos políticos para além do estado assentados em uma distribuição menos hegemônica de autoridade.

Indigenidade como categoria de análise

Há ao menos três razões para se engajar com a indigenidade como categoria de análise para pensar além do estado. Há os motivos empíricos: lutas indígenas que desafiamcom sucesso estados soberanos são poderosas demais para não impactaremde forma significativa a política global. Depois, do ponto de vista histórico, a indigenidade é intrinsecamente relacional à formação dos estados, o que faz dela um instrumento valioso para pensar sobre reorganizações pós-nacionais. Por fim, no nível teórico, trata-se de um local estratégico a partir de onde se pode desafiar as fronteiras disciplinares das RI.

Há uma necessidade empírica de integrar política indígena ao estudo de RI devido a seus impactos imediatos em questões globais. Do Ártico ao Amazonas, comunidades indígenas estão lutando contra indústrias extrativas no seus territórios autônomos e resistindo a políticas predatórias (BANERJEE, 2012; BEBBINGTON; BEBBINGTON, 2011). Movimentos indígenas no Equador 
evoluíram para partidos políticos formais com a criação do Pachakutik em 1996 (BECKER, 2011), enquanto os Inuit conseguiram criar práticas de autogoverno que estão entre as mais avançadas do mundo (SHADIAN, 2013). Na medida em que as diferenças entre políticas de direita e esquerda tornam-se confusas, grupos indígenas emergem como lugares globais de contestação contra políticas de estado, oferecendo a esperança de éticas alternativas de governança (SANTOS, 2012). Sistemas de justiça indígena estão reformulando a autoridade judicial, visibilizando contratos sociais colaborativos independentes do estado. Territorialidades indígenas desafiam não apenas a autoridade individual dos estados dentro das fronteiras nacionais, mas a organização da política global em torno da soberania. De fato, demandas indígenas buscam tanto a redistribuição de direitos quanto o desarraigamento da concentração de poder no estado.

$\mathrm{O}$ imperativo histórico de trazer a indigenidade para as $\mathrm{RI}$ vem de seu papel em tantos processos de formação de estados. A invenção de povos indígenas como selvagens a serem civilizados levou a políticas coloniais de expropriação apoiadas pela doutrina do descobrimento. A indigenidade era a antítese imaginada da modernidade europeia, atemporal e apolítica, resumindo uma ausência inventada do contrato social que ostensivamente precedeu o estado (europeu). A indigenidade se refere aos nativos não civilizados que não pertencem ao projeto "moderno" de construção do estado. O termo se aplica aos que precedem o estado moderno. Assim, a indigenidadeespelha a modernidade como o seuOutro "cultural" contra o qual a história da nação europeia se desenrola. É intrinsecamente relacional ao estado, e portanto, vital para uma disciplina dedicada ao estudo das relações entre estados. Dispensar a política indígena com base no seu status de minorias é um engano, pois a indigenidade se refere, antes de tudo, ao estado.

Esta interligação conceitual é crucial. A relação co-constitutiva entre indigenidade e estado explica a proliferação mundial de reivindicações indígenas diversas. ${ }^{1} \mathrm{O}$ denominador comum de políticas indígenas no mundo é

\footnotetext{
${ }^{1}$ Como a indigenidade refere-se ao estado tanto quanto às pessoas fora dele, as contranarrativas indígenas para a formação do estado variam muito de acordo com o contexto, tempo, e região (Engelbert 2009). "Indígena" é uma identidade contestada, heterogênea e fluida, referindo menos a um quem/o que constitutivo do que à alteridade implicada pelo termo (Canessa
} 
o legado colonial dos estados-nação. Embora os colonialismos variem do Sudoeste Asiático à América Latina, provincializar as estruturas políticas europeias é um desafio compartilhado (CHAKRABARTY, 2000). É precisamente por serem intrínsecas à emergência do estado e contestarem sua autoridade que a política indígena pode contribuir com críticas que são distintas de abordagens feministas ou raciais. Enquanto demandas embasadas em gênero e raça almejam expandir o acesso ao estado, reivindicações indígenas, por sua vez, demandam direitos autônomos em relação ao estado. A indigenidade pede menos estado, não mais. Com efeito, o fato de estarem fora do estado e serem anteriores aele torna os pontos de vista indígenas lugares valiosos para imaginários do pós-estatal.

Consequentemente, a indigenidade perturba algumas das bases epistemológicas centrais das RI. A indigenidade é um local estratégico de onde se pode pensar diferentemente, pois sua precedência sobre o estado moderno implica em uma legitimidade política para além dele. Experiências indígenas complementam histórias nacionais oficiais com narrativas esquecidas ou reprimidas. Nesse processo, elas trazem outras epistemologias, desestabilizando conceitualizações estadocêntricas do político. O "anterior" que Saskia Sassen (2008) vê desafiando a soberania é precisamente a indigenidade. Desta forma, a indigenidade envolve dimensões territoriais e históricas que tampouco o gênero ou a raça oferecem, e pensa a autoridade política para além do estado.

A imaginação espacial dos estados como sendo modernos e globais, em contraste com indigenidades, imaginadas como não-políticas e isoladas, não deixam de ver apenas o impacto da política indígena, mas também a essência do estado. A indigenidade é crucial para lidar com questões pós-coloniais como as levantadas por Dipesh Chakrabarty (2000). O estado moderno emerge como fundamentalmente inadequado para reconhecer a amplitude de projetos políticos alternativos. A indigenidade, como uma categoria colonial central para a construção do estado, fornece ferramentas para historicizar o estado e a

2005). O direito internacional propõe apenas regras gerais para identificar a indigenidade (precedência, linguagem, terras ancestrais), que é atribuída em grande medida à auto-definição. 
soberania. Além disso, se epistemologias de-coloniais são um ponto de partida indispensável para ir além do estadocentrismo europeu, experiências indígenas complementam a teoria com a práxis. A autonomia indígena territorial e de jurisdição, por exemplo, postula um espaço político para além da soberania estatal. Tais experiências libertam imaginários políticos da epistemologia tradicional do estado-nação (BIOLSI, 2005), possibilitando pensar um mundo que não é baseado em estados. Trazer estudos indígenas às RI determina nossa habilidade de envolver a variedade de práticas políticas que estão florescendo sob a superfície. Ademais, abre debates epistemológicos que podem transformar o autoentendimento das RI. A ebulição das lutas indígenas não apenas confirma a inadequação dos estados, mas também oferece experiências concretas do que o internacional pode realmente estar para dentro e para além deles.

\section{Práticas indígenas do internacional}

A interseção de abordagens feministas com perspectivas indígenas oferece uma posição estratégica para mirar a política global. Explorarei esta interseção com a análise de um estudo de caso das lutas das mulheres indígenas no Equador. As manobras legais das mulheres kichwa nos planaltos de Chimborazo não se apoiam somente no internacional, mas também constituem um espaço legal desnacionalizado, desafiando os imaginários esperados da soberania. Esta seção postula, primeiramente, a dimensão internacional das reivindicações indígenas, para então analisar os mecanismos pelos quais as mulheres kichwa criam novos direitos legais.

\section{Internacionalismo indígena}

Não há nada novo sobre a dimensão internacional da política indígena. As RI podem não ter chegado lá ainda, mas historiadores traçam a conexão entre povos indígenas e o direito internacional à relação entre o direito indígena e 0 direito imposto na expansão da soberania dos colonos (BENTON, 2009; FORD, 2010). Pesquisadores de estudos indígenas forneceram vastas evidências de como populações nativas articularam seus direitos coletivos frente ao direito colonial. Mulheres indígenas na Quito colonial habilmente navegaram entre 
sistemas legais (GAUDERMAN, 2003), enquanto na Nova Inglaterra os Pequots do Leste estabeleceram sua reserva por meio de um acordo legal em 1683 (DEN OUDEN, 2012). No início do século XIX, o Juiz da Suprema Corte americana, John Marshall, salientou a soberania nativa em dois casos entre a Nação Cherokee e o estado de Geórgia. Ele definiu "o caráter dos Cherokee como um estado, como uma comunidade política distinta (...) se autogovernando", estabelecendo que as leis da Geórgia não eram de aplicação compulsória à nação Cherokee (BIOLSI, 2005, p.242). Até hoje tal decisão permanece como ponto contencioso legal que o governo federal dos Estados Unidos reconheça nativos americanos como estados independentes enquanto estrategicamente Ihes nega o direito de praticar relações internacionais (DELORIA JR.; LYTLE, 1998). Vine Deloris Jr. (2006) corretamente denuncia batalhas judiciais entre grupos nativos e o estado que eram nada mais que uma "conquista mascarada de direito", e Amy Den Ouden (2012) detalha a violência legal do estado colonial. Reservas são, não obstante, uma terra soberana da qual se pode praticar a contestação legal. $O$ internacional tem sido o local preferido, talvez inevitavelmente, de onde se realiza a contestação indígena pois a política indígenatem se situado historicamente fora do estado. A resistência legal indígena não deve ser vista, portanto, como um fenômeno novo ou singular (BELMESSOUS, 2011). Ao invés disso, lutas contemporâneas estão embasadas em 500 anos de estratégias internacionais elaboradas. A evicção europeia de terras nativas para a formação do estado moderno dependeu da invalidação de sistemas de autoridade existentes. Grupos indígenas então (e hoje) eram mantidos fora do estado, e sua contestação produziu legalidades sofisticadas para desafiar a autoridade soberana auto atribuída do estado. $O$ ativismo legal indígena do século $\mathrm{XVI}$ em diante era tão dinâmico que pesquisadores argumentam que as justificativas legais europeias deveriam ser entendidas em parte como pedidos reconvencionais em vez de discursos originais. Longe de serem observadores passivos, povos nativos eram ativos em fazer, mudar e interpretar o direito colonial e, por extensão, moldar a ordem internacional (BENTON, 2001). Reivindicações indígenas são, assim, anteriores ao completo estabelecimento dos estados modernos. 
Políticas indígenas vêm se tornando mais visíveis na política convencional ao longo das últimas três décadas, desde que ganharam espaço no sistema internacional de direitos humanos (ANAYA, 2004). Nas Nações Unidas (ONU), a participação de representantes de organizações indígenas no Grupo de Trabalho sobre as Populações Indígenas (WGIP) pulou de 48 a 500 entre 1983 e 2005 (CORNTASSEL, 2007: 153; ESCÁRCEGA, 2010). O Fórum Permanente das Nações Unidas para Questões Indígenas (UNPFII), que tem reunido povos indígenas anualmente em Nova lorque desde 2002, assessora o Fórum Econômico e Social das Nações Unidas (ECOSOC). A proliferação de órgãos da ONU se expandiu significativamente durante as duas Décadas da ONU para Direitos Indígenas, criando mecanismos de expertise e de monitoramento, além de consolidar normas. Intrínsecas aos direitos humanos, as reivindicações indígenas ganharam ímpeto à medida que o sistema internacional de direitos humanos se consolidou (NIEZEN, 2003).

Desde 1989, povos indígenas têm feito uso vigoroso da Convenção 169 da Organização Internacional do Trabalho (OIT) para defender seus direitos em cortes internacionais. Em 2007, a Declaração das Nações Unidas sobre os Direitos dos Povos Indígenas (UNDRIP) - o tratado mais importante para os direitos indígenas no mundo desde 1985 - confirmou a legitimidade global das reivindicações em prol da autodeterminação. ${ }^{2}$ A UNDRIP foi o instrumento de direitos humanos que teve o mais longo debate na história da ONU, estendendose por duas décadas consecutivas. O reconhecimento de direitos coletivos à consulta prévia geraram desconforto, mas o que realmente bloqueou o processo foi a arraigada resistência dos estados em ceder autonomia sobre territórios indígenas. A Declaração selou o reconhecimento universal do princípio de autodeterminação (Artigo 3) e formalizou direitos às terras, territórios e recursos (Artigos 25 a 30). Isto demandou reconhecer sistemas de autoridade alternativos complexos em territórios contidos pelo estado soberano. ${ }^{3}$ A solução para as

\footnotetext{
${ }^{2}$ As negociações duraram mais de 11 sessões anuais para atingir um consenso, e os únicos quatro países que se opuseram foram Austrália, Canadá, Nova Zelândia e os EUA. Adotada por 144 países, a Declaração foi o primeiro documento legal dedicado a direitos indígenas no sistema ONU.

${ }^{3}$ A maioria dos estrados-membros reagiu ao Artigo 46, o mais contencioso, especificando que a Declaração não poderia ser interpretada de qualquer forma que prejudicasse a soberania territorial dos estados. Austrália, Nova Zelândia, Canada e EUA votaram contra o tratado em
} 
negociações contenciosas sobre territórios foi um artigo final especificando que nenhuma parte da Declaração pode ser entendida como minando de nenhuma forma a soberania e a integridade territorial dos estados-membros (Artigo 47). Tomando a forma clássica de direitos humanos internacionais, a Declaração permaneceu ambígua e, no entanto, a autodeterminação indígena ganhou reconhecimento global. A emergência de normas internacionais protegendo os direitos indígenas não foi uma concessão de estados-membros bem intencionados na ONU, mas sim fruto de um poderoso movimento indígena global (MORGAN, 2011). ${ }^{4}$

Assim como em tempos coloniais de despojamento de terras, o propósito atual de desenvolver estratégias legais internacionais é contestar o estadonação nos âmbitos locais, e a proliferação de mecanismos internacionais, legitimando a autonomia indígena, infiltra-se dentro dos estados enquadrando as jurisdições domésticas. Todo estado na América Latina agora reconhece algum grau de autonomia indígena, de sistemas independentes de justiça a autonomia territorial. A comunidade Sarayaku na Amazônia Equatorial construiu uma rede avançada de aliados internos para resistir a indústrias extrativas em seus territórios ancestrais. No caso da barragem de Belo Monte no Brasil, a pressão indígena pelo respeito às leis de consultas prévias resultaram em casos complexos nos tribunais envolvendo cortes locais e federais, a Organização dos Estados Americanos e normas globais. No Peru, o direito internacional foi invocado com tamanha força que o governo adotou leis integrando mecanismos de consultas prévias na Constituição de 2011. Lutas contemporâneas pela autodeterminação indígena impactam os contornos do estado mais frequentemente e mais profundamente do que usualmente se quer reconhecer.

É em parte por estarem as politicas indígenas tão envolvidas na arena internacional que as Relações Internacionais devem levá-las mais seriamente

2007, e alguns, desde então, revisaram suas posições. Em 2011, por exemplo, a administração Obama reconheceu a UNDRIP.

${ }^{4} \mathrm{O}$ ativismo global indígena é dinâmico para além dos corredores formais das organizações intergovernamentais, como mostra a globalização da mídia indígena, como a Rede Mundial de Radiodifusores de Televisão Indígena e a proliferação de encontros hemisféricos. Ambos as Cúpulas Continentais dos Povos e Nacionalidades Indígenas de AbyaYala (Becker 2008) e a Cúpula Continental de Comunicação Indígena nas Américas testemunham a influência indígena na formulação de políticas públicas através das fronteiras. 
em conta. E também porque, conforme se desdobram, as dinâmicas indígenas impactam o conteúdo da política global. Em particular, elas moldam o que a soberania implica e onde ela se localiza. As formas pelas quais as mulheres indígenas usam a política global para defender seus direitos em comunidades locais revelam quanto o internacional é articulado em contextos nativos. As estratégias internacionais de um pequeno grupo de mulheres kichwa no Equador são exemplares. Sua posicionalidade na intersecção de gênero e etnicidade busca reorganizar a autoridade de forma autônoma em relação ao estado, combinando direitos coletivos indígenas e normas globais de direitos humanos.

\section{Mulheres kichwa reunindo direitos legais}

No Equador, um grupo de mulheres kichwa valeu-se do direito internacional como a principal ferramenta para promover seus direitos dentro de sistemas de justiça ancestrais. A Red de Mujeres Kichwas de Chimborazo (Rede de Mulheres Kichwas de Chimborazo), localizada no planalto central do Equador, é liderada por um grupo de cerca de 100 mulheres, a maioria delas camponesas, bilíngues em kichwa e espanhol, e majoritariamente analfabetas. Reivindicações indígenas frequentemente invocavam a Convenção 169 da OIT, enquanto demandas feministas reiteravam princípios da Convenção sobre a Eliminação de Todas as Formas de Violência contra as Mulheres (CEDAW) para defender vidas sem violência. Mas as mulheres kichwa estavam ativamente buscando a incorporação dos direitos globais das mulheres nos direitos coletivos. Sentindose tolhidas entre o racismo das instituições do estado e as práticas costumeiras prejudiciaisàs mulheres, elas usaram as normas de direito internacional para lutar por seus direitos interseccionais como mulheres indígenas.

A oportunidade surgiu em 2008, quando o Presidente Rafael Correa iniciou uma reforma constitucional. A Red de Mujeres Kichwas de Chimborazo estivera lutando contra a falta de acesso das mulheres à justiça após um caso de violência doméstica, dois anos antes, ter levantado controvérsias na província. Depois de bater na mãe de seus filhos, o Congressista Pachakutik ${ }^{5}$

\footnotetext{
${ }^{5}$ O Pachakutik, fundado em 1996, é o partido eleitoral dos movimentos indígenas do Equador (ver Becker 2011).
} 
Estuardo Remache havia demandado que as acusações contra ele fossem transferidas do sistema de justiça comum para a justiça comunitária indígena, evadindo, assim, sua responsabilidade (PICQ, 2012). Quando o Presidente Correa convidou os cidadãos equatorianos a contribuir com agendas para serem debatidas em um processo constitucional democrático em Monte Cristi, as mulheres kichwa já estavam trabalhando em uma agenda para buscar direitos legais para si.

Assim como o movimento indígena equatoriano estrategicamente invocou os direitos humanos internacionais para defender interesses subnacionais, as mulheres kichwa trespassaram as jurisdições nacionais ao buscarem uma linguagem legal que apoiasse sua causa. Cristina Cucuri, a única membro do grupo com educação superior, navegou na internet por dias buscando tratados internacionais ou constituições estrangeiras que explicitamente definissem os direitos de mulheres indígenas. Selecionando tratados internacionais e constituições nacionais da região no Google, ela encontrou legislação específica para povos indígenas e amplos direitosdas mulheres, mas pouco na intersecção entre eles. ${ }^{6}$ A Declaração da ONU de 2007 não vai além de chamar especial atenção para os direitos de mulheres (Artigo 22). Na Bolívia, a nova Constituição, aprovada sob o mandato do Presidente indígena Evo Morales, representou uma melhoria sólida para as populações nativas. No entanto, os direitos indígenas se expandiram sem muita consideração para questões de gênero.

Mulheres kichwa combinaram normas internacionaise direito nacional para construir seu caso. A Constituição de 1998 formalmente reconhecia direitos coletivos, notadamente a justiça indígena. A partir de então, o desafio era fazer os direitos coletivos respeitarem normas de gênero como aquelas promovidas na CEDAW. Seu objetivo era garantir a participação e tomada de decisão das mulheres nos assuntos da comunidade. Para atingi-lo, a estratégia era pressionar o sistema de justiça equatoriano para requerer que os sistemas de justiça indígena se alinhassem com normas internacionais de igualdade de

\footnotetext{
${ }^{6}$ As mulheres kichwa se inspiraram, majoritariamente, na Lei Zapatista sobre Mulheres em Chiapas de 1994, no México, que estabeleceu dez direitos específicos para mulheres de liderança política a castigo para violência sexual. Sua dimensão consuetudinária, no entanto, teve pouco peso no direito internacional.
} 
gênero. Aproveitando a oportunidade de uma reforma constitucional, as mulheres kichwa procuraram conectar o direito internacional sobre direitos das mulheres com a legislação doméstica de direitos coletivos. Elas desconsideraram as recomendações de uma advogada especialista em direitos coletivos que declarou a ideia inoperável sob o pretexto de que gênero era parte dos direitos universais e, portanto, irreconciliável com direitos culturais excepcionais. Ao invés disso, elas navegaram por três escalas de autoridade legal para inventar seus direitos e torná-los lei. As mulheres indígenas estão protegendo direitos culturais e mudando sua cultura, demonstrando que isso é menos contraditório do que pode parecer à primeira vista.

Armadas com dois conjuntos de normas internacionais, as mulheres mesclaram a linguagem de gênero da CEDAW com os direitos indígenas estabelecidos na UNDRIP para esboçar uma proposta. $\mathrm{Na}$ abertura da Assembleia Constituinte, elas se dirigiram ao seu presidente, Alberto Acosta, e Ihe entregaram um documento explicando a violência embutida na desigualdade de gênero em suas comunidades e reivindicaram que os direitos coletivos respeitassem as vozes das mulheres. Por meses elas se revezaram viajando para a cidade costeira de Montecristi, onde o processo da assembleia ocorria, para promover seus esforços de advocacia. Elas deixaram seus filhos e suas terras, algumas pela primeira vez, e realizaram viagens de dez horas de ônibus para pressionar os políticos de mais alto escalão no país. Seu discurso para ministros e membros da assembleia enfatizou a responsabilidade do estado equatoriano em honrar as normas de direitos humanos que haviam sido ratificadas em âmbito internacional. Em particular, elas insistiram na adoção de linguagem explícita "garantindo a participação e tomada de decisão às mulheres" em leis relativas a direitos coletivos, cultura e justiça indígena (Constituição do Equador).

O foco do grupo era reformar seus próprios sistemas autônomos de justiça. Elas não buscavam solucionar as discrepâncias de gênero no aparato judiciário do estado. Ao invés disso, elas desejavam explicitamente integrar direitos internacionais das mulheres em sistemas subnacionais indígenas, desconsiderando se o estado-nação adotava tais leis. O raciocínio das mulheres era direto: se as normas de direitos humanos internacionais são realmente 
universais, então elas são válidas em níveis subnacionais, incluindo aí as práticas culturais mais ancestrais nos Andes. De acordo com a Constituição, tratados internacionais ratificados pelo Equador têm validade legal. Portanto, por ser a justiça indígena totalmente autônoma, ela deve - assim como o estado respeitar os tratados internacionais de direitos humanos. A demanda por respeito aos direitos humanos das mulheres indígenas era perfeitamente argumentável por meio de dedução legal, mesmo na ausência de precedentes no sistema legal nacional. A inovação chave foi que a soberania legal do estado foi ignorada, levando os sistemas de justiça indígenas subnacionais a serem explicitamente responsabilizados pelos direitos internacionais das mulheres. Como resultado, as mulheres kichwa fundiram discursos internacionais de igualdade de gênero com normas de autonomia cultural, equilibrando e integrando o direito internacional à justiça indígena. Na prática, elas fortaleceram o excepcionalismo cultural por meio do emprego ágil do sistema normativo dos direitos internacionais das mulheres. Em nível conceitual, sua estratégia política conciliou debates antigos que opõem multiculturalismo e igualdade de gênero (OKIN, 1999; BENHABIB, 2002; SONG, 2007), tecendo o gênero na cultura.

Invocar o direito internacional foi suficiente para pressionar com sucesso o estado. O grupo das mulheres apresentou cartas formais exigindo que a Assembleia Constituinte integrasse a linguagem internacional sobre paridade de gênero e igualdade em seis artigos sobre direitos coletivos (Artigos 1, 9, 10, 16, 17, 22). Inspiradas na CEDAW, sua escrita demandava que a cultura indígena "eliminasse todas as formas de discriminação e violência contra meninas, adolescentes e mulheres adultas" (Artigo 26). Elas insistiram que linguagem explícita sobre igualdade de gênero fosse integrada nos artigos sobre direitos coletivos ao longo da nova constituição. Três artigos agora incluem linguagem específica de gênero para garantir a participação igualitária das mulheres. $O$ novo artigo sobre autonomia judicial indígena (Artigo 171) requer a "garantia da participação e tomada de decisão das mulheres". A paridade de gênero também foi adicionada em artigos sobre direitos coletivos e cultura. Depois de muita insistência das mulheres kichwa, o longo Artigo 57 sobre direitos coletivos de povos indígenas, foi complementado com uma linha final: "O estado vai garantir 
a aplicação destes direitos coletivos sem nenhuma discriminação, em condições de igualdade e equidade entre mulheres e homens."

A importância do ativismo político das mulheres kichwa em torno dos direitos humanos é múltipla, demonstrando notavelmente a complementariedade, e não a incompatibilidade, entre os direitos universais das mulheres e os direitos coletivos à cultura. Para enfatizar o internacionalismo da política indígena, ao menos duas considerações precisam ser salientadas.

Primeiramente, os povos indígenas fazem uso extensivo e regular de normas e organizações internacionais em sua prática política cotidiana. Por mais locais e tradicionais que possam ser, as experiências indígenas revelam um uso sofisticado do direito internacional. As mulheres kichwa valeram-se do direito internacional para ter êxito em tornar a justiça indígena responsável pelos direitos das mulheres. Este uso do direito internacional é relevante em um país onde metade da população descende de indígenas. Mostra a relevância local dos tratados internacionais e o internacionalismo habilidoso das chamadas sociedades tradicionais.

Em segundo lugar, a política indígena não está apenas adaptando-se às normas internacionais, mas também moldando a prática internacional. As mulheres kichwa de Chimborazo podem ter buscado justiça local, mas conforme instrumentalizavam políticas nacionais e internacionais, elas redefiniram a progressão da responsabilidade legal do global ao local. Elas tornaram o local qual seja as formas indígenas de justiça - responsável perante o direito internacional. A jurisdição do estado foi usada apenas para formalizar o novo arranjo legal entre direitos indígena e global. É como se o estado estivesse envolvido como um terceiro para testemunhar as responsabilidades internacionais indígenas. Sua proposta de política emergiu em contextos nativos indígenas, mas resultaram em reformas legais de amplo escopo político e intelectual. Não somente a Constituição Equatoriana tornou-se a primeira das Américas a explicitamente reconhecer a plena participação e tomada de decisão das mulheres em direitos coletivos e culturais, mas também o estado foi usado com árbitro, registrando a responsabilidade legal entre jurisdições autônomas subnacionais e o sistema global de direitos humanos. O estado-nação avançou no reconhecimento da soberania legal dos sistemas de justiça indígena, 
validando sua responsabilidade legal também na arena internacional. Neste sentido, enquadrar direitos coletivos em relação a normas internacionais de igualdade de gênero reformou muito mais do que os direitos das mulheres indígenas. Expandiu a soberania legal de grupos indígenas para além das fronteiras nacionais para torná-los diretamente responsáveis perante o direito internacional e sujeitos a ele.

A experiência de mulheres indígenas no Equador demonstra como os interesses locais usam o internacional para enfraquecer a autoridade legal do estado. Este estudo de caso ilustra o que é o internacional quando redirecionamos nosso olhar "por dentro" e "para além" do estado. Também desvela o amplo impacto da política das mulheres indígenas para fora do Equador. Suas estratégias políticas situam a política global dentro de geografias indígenas, fornecendo um roteiro prático para desenvolver as soberanias legais para além de uma política estadocêntrica.

\section{Deslocando a soberania legal à moda indígena}

As práticas das mulheres indígenas no Equador contribuem para repensar a soberania para além do estadocentrismo. A triangulação da autoridade jurídica entre legalidades em nível subnacional, nacional e internacional indica escalas de soberania que competem entre si, se complementam e se sobrepõem. Esta tríade não precisa minar totalmente o estado, mas ela borra as fronteiras entre formas de governança internacional e local, enquanto aponta para esferas alternativas de soberania dentro do estado-nação.

A articulação da autoridade legal entre direito doméstico, normas internacionais e justiça indígena revela uma prática complexa e com muitas camadas de soberanias para além do estado. Nesse processo, a política indígena desloca a soberania legal do estado, realocando-a entre atores indígenas e autônomos. Assim, dinâmicas indígenas de soberania podem ser comparadas ao supranacionalismo europeu, pois cada um coloca desafios importantes e distintos às práticas de estatalidade e à governança global.

A política das mulheres indígenas expõe a concomitância de três escalas de autoridade legal - indígena, nacional e internacional -, cada uma delas 
envolvendo uma jurisdição própria. As mulheres kichwa triangularam estratégias legais de forma certeira. Elas usaram o direito internacional para mirar o estado e expandir a autonomia legal - e a soberania -da justiça indígena. Elas triangularam com as autoridades internacional e nacional para atingir seu objetivo em nível subnacional. Suas estratégias conceberam a soberania estatal não como um fim, mas como meio para fortalecer a responsabilidade internacional no âmbito dos espaços indígenas. O sistema normativo global fornece uma fonte para reivindicações de direitos universalmente legítimos, enquanto o estado é o veículo que codifica os direitos das mulheres indígenas como aspectos da jurisdição indígena autônoma.

Dois pontos são centrais aqui. Primeiro, esta articulação de múltiplas escalas de autoridade legal torna a forma homogênea da soberania estatal obsoleta. Em segundo lugar, a agilidade política das mulheres indígenas manobrando três sistemas de justiça revela sua potencial complementaridade. As normas internacionais, as constituições estatais e os sistemas autônomos de justiça coexistem como fontes complementares de direitos, inspirando possibilidades de soberanias no plural. As mulheres triangulam responsabilidades para compensar brechas na jurisdição judicial em qualquer nível. As jurisdições representam diferentes domínios políticos, prioridades e capacidades de coerção. Elas são, não obstante, concomitantes e interrelacionadas. A conexão subsequente de autoridades legais mostra que colocar estes três conjuntos de soberanias em diálogo é uma forma de expandir direitos. Se esta tríade legal indica múltiplos titulares da soberania legal, ela inevitavelmente desestabiliza ideias que concebem todos os estados como tendo soberania igual sobre seus territórios (uns em relação aos outros) ou que todos os territórios dos estados são espaços de jurisdições exclusivas com "integridade territorial". Por exemplo, desafia a noção de Carl Schmitt (2006) de exceção jurídica como ingrediente chave da soberania. Schmitt foi celebrado ao identificar a autonomia do político por meio do conceito de exceção de soberania - a soberania não estaria apenas na criação das regras, mas na criação da exceção à regra. Numa visão oposta à de Schmitt, aqui as normas internacionais estão sendo usadas para fortalecer estados alternativos de exceção à soberania do estado. Estas não refletem meras soberanias subnacionais, mas soberanias 
indígenas, que são intrinsecamente externas ao sistema de estados. Neste sentido, a emergência de legalidades indígenas responsáveis perante as normas globais demanda reconfigurações conceituais da soberania, que deixa, assim, de ser um monopólio legal dos estados. Tais processos simbolizam a possibilidade de autoridades parcialmente autônomas, competirem dentro do próprio estado. Elas reconfiguram a soberania como plural, com polos por dentro e por fora, contendo conjuntos desiguais e variados de competências, bem como uma multiplicidade de geografias não limitadas por fronteiras estatais. Quando as mulheres kichwa consagram direitos globais dentro de contextos indígenas elas estão validando soberanias alternativas independentes do estado equatoriano. Esta redistribuição de soberania dentro das fronteiras estatais aponta para formas inovadoras de estatalidade em geral.

Minha análise sugere que processos ocorrendo no âmago de geografias indígenas também são parte de reconfigurações globais - mesmo se tendem a ser construídas como não relacionadas àpolítica global - porque refletem e remodelam significados e sistemas internacionais. O trabalho de Saskia Sassen (2008) expõe como as transformações globais estão deslocando capacidades nacionais. Ela aponta que tais reconfigurações não podem ser totalmente compreendidas se estudadas apenas em uma escala global sem se olhar para dentro delas, para examinar dinâmicas desenvolvendo-se localmente. A morfologia dos estados - e as relações entre eles - tem sido complicada pelas reconfigurações políticas que ocorrem do nível internacional ao subnacional. As mulheres kichwa no Equador estão provocando reconfigurações de autoridade, complexas do ponto de vista geográfico, para muito além do estado-nação. A autodeterminação indígena envolve um processo de desnacionalização judicial que desafia a associação entre autoridade soberana e território. A justiça indígena é internacional porque é validada por sistemas globais de significado, mas também por consistir em uma prática de justiça desterritorializada. Esta é uma das razões por que a coordenação entre sistemas indígenas fluidos e a justiça comum do estado, rígida e territorialmente limitada, permanece um desafio central para estados plurinacionais. Este capítulo sugere que a política indígena de autodeterminação é uma das colocações onde a soberania é obrigada a se reinventar. A autonomia indígena não representa o fim do estado 
que, conforme Dipesh Chakrabarty (2000) postula, é indispensável. Ela implica, no entanto, em uma reconfiguração de sua autoridade demandando, consequentemente, outras conceituações de formas de soberania compartilhada. Conforme a autoridade legal migra para atores não-estatais em níveis subnacionais, ela desloca um pressuposto chave da soberania: a jurisdição exclusiva do estado sobre seu território. Na exceção jurídica, a justiça indígena ganha crescente relevância para teorias de soberania. A complexidade conceitual advém do fato de que os sistemas indígenas de justiça esculpem um estado de exceção autorizado pelo próprio estado soberano. Se a justiça indígena adquire o direito de exceção jurídica, ela não é mais totalmente contida pelo estado ou subordinada a ele. Sheryl Lightfoot (2016) vê os direitos indígenas implicando em mudanças críticas para o sistema vestfaliano, abrindo espaço para uma prática plurinacional onde a soberania é compartilhada entre estados e povos indígenas. Pode não ser possível reivindicar soberania plena, mas os sistemas de justiça indígena, como estão agora na América Latina, permitem estados de exceção no sentido mais fundamental de Schmitt. Quando a constituição de 1998 do Equador reconheceu a justiça indígena, ela implicitamente reconheceu a autoridade dos 13 povos e nacionalidades indígenas compreendidos dentro de suas fronteiras. Isto não é um multiculturalismo raso que tolera identidades diversas. Ao invés disso, a constituição permite a coexistência de vários sistemas de justiça autônomos que revelam camadas de autoridade dentro de um estado plural em mais de uma dimensão. Abordagens contemporâneas dapolítica global estão carregadas de entendimentos sobre soberania que não correspondem aos mundos da vida que atuam moldando a formação de estados na periferia política do sistema-mundo. De fato, a política indígena na América Latina apoia noções de que a soberania não é inerentemente territorial ou invariavelmente baseada no estado. É precisamente devido à ameaça que ela representa para a soberania, que os estados resistem intensamente à autodeterminação nas negociações globais. De fato, a Década Internacional dos Povos Indígenas do Mundo (1995-2004 e 2005-2015) não logrou chegar a um consenso para produzir um tratado internacional precisamente devido a esta razão, e a Declaração tornou-se o tratado alvo de mais longo debate na história da ONU, como já destacado. A 
justiça indígena envolve uma esfera de autoridade autônoma dos estados, mas não necessariamente mina a soberania convencional. Ela, no entanto, a complica. Estados podem continuar como os repositórios da autoridade soberana, mas sua reivindicação, outrora exclusiva, de direito de exceção, agora pode ser capturada e usada por outros.

Contar a história das mulheres kichwa explicita as muitas configurações que a soberania, em suas reformatações globais, pode assumir na prática. $O$ florescimento de sistemas de justiça indígena e sua responsabilidade perante regimes internacionais implicam em reconfigurações significativas da soberania legal para além da América Latina. Europeístas abordaram a reconfiguração da soberania estatal de cima para baixo por meio da realocação da autoridade do estado para o nível supranacional da UE. Jürgen Habermas (2001) viu este "desempoderamento" do estado-nação por instituições supranacionais como um caminho em direção a uma "constelação pós-nacional" para além da soberania (2001: 81). Outros defenderam o papel de regiões subestatais em tal estrutura supranacional. Proponentes da governança global defenderam o papel dos tratados internacionais no desenho e implementação de uma política doméstica internacional (ARCHIBUGI; HELD, 1995). As comunidades epistêmicas sugerem uma imagem dinâmica de interações políticas entre processos políticos que persiste nos níveis nacional, internacional e global. Assim como a Europa contribuiu com uma prática do que pode ser uma política global após o estadonação, a América Latina está contribuindo com suas próprias perspectivas alternativas - de baixo para cima.

Levar em conta a etnopolítica para analisar a constelação pós-nacional permite discernir a possibilidade de dinâmicas equivalentes desde dentro do estado. Enquanto a UE provocou reconfigurações da soberania legal em prol de instituições supranacionais, a justiça indígena na América Latina está gerando reformulações da soberania legal para esferas políticas contidas pelo estado, mas significativamente independentes dele. No caso da UE, a soberania foi realocada para cima, enquanto no Equador a soberania está sendo realocada a partir de baixo. A autodeterminação indígena é crucial para apreender as RI porque tais processos desvelam caminhos alternativos para repensar a essência e a silhueta do estado, o sujeito quintessencial de análise do campo de RI. 
Ambas as visões alegam que fragmentos da soberania estão migrando para longe do estado. As dinâmicas do supranacionalismo europeu são, em um sentido, muito similares - ainda que opostas - àquelas desencadeadas pela política indígena na América Latina. A UE orquestrou um progressivo desmantelamento da soberania estatal de cima para baixo, ganhando autoridade sobre a política financeira, moeda e códigos legais. Na América Latina, a proliferação do pluralismo legal força uma realocação similar da autoridade estatal, exceto pelo fato de que se dirige para dentro, ao longo de linhas locais e étnicas, ao invés de adotar um formato supranacional. Isto permite que bolsões ou zonas de soberania se materializem dentro do estado, expondo uma redistribuição de soberania legal para atores não-estatais que estão ao mesmo tempo dentro e além do estado. No entanto, a maioria das abordagens de RI olha para fora ou acima do estado e não considera abordagens indígenas que envolvem complexas renegociações da autoridade estatal. Raros são os estudiosos que identificam a indigenidade como um local intrínseco de contestação internacional. Mas aqui vemos como olhares indígenas de baixo/dentro/além do estado-nação revelam uma espacialidade do poder alterada não apenas por dinâmicas supranacionais, mas também por posicionalidades indígenas situadas dentro de suas fronteiras, mas para além de sua autoridade.

Meu propósito em dar atenção particular à migração da soberania é enfatizar a relevância conceitual da indigenidade para o estudo de RI. Experiências indígenas na esfera política não devem ser compreendidas meramente como um antídoto "cultural". Enquanto tais considerações culturais existem, a etnicidade tem evoluído para ser um recurso político (COMAROFF; COMAROFF, 2009) que molda tanto as organizações internacionais (MORGAN, 2011), como os estados (SIERRA, 2005). A autonomia legal indígena, um marco histórico no reconhecimento da autodeterminação, está relacionada ao redesenho do conteúdo e perfil da autoridade estatal. É, nesse sentido, um elemento crucial na política global que estudiosos, se buscam explicar o mundo onde vivemos, não podem mais se dar ao luxo de ignorar.

\section{Conclusão}


A atenção à indigenidade é valiosa para as RI porque empodera novas formas de pesquisa crítica. São pelo menos duas as contribuições das formas indígenas de vivenciar. Primeiro, envolver perspectivas etnográficas visibiliza formas de fazer RI para além de Vestfália que tendem a ser invisibilizadas. Em segundo lugar, experiências indígenas desestabilizam pressupostos sobre o que constitui o internacional. A indigenidade é uma categoria chave de análise para romper o estadocentrismo. Em particular, é um local estratégico para o desenvolvimento de contra-narrativas que transgridam as fronteiras disciplinares. A história das "vizinhanças pós-nacionais" (CHATTERJEE, 2010: 167) no planalto andino do Equador mostra com o que a soberania pode se parecer quando separada do estado. Se a justiça indígena deve ser entendida como uma forma de autoridade local autônoma em relação ao estado, talvez a soberania possa ser repensada como múltipla e plural. Tais compreensões sobre os rearranjos da autoridade legal ocorrendo na América Latina fornecem exemplos úteis que redefinem o lugar da soberania em geral. Movimentos contemporâneos indígenas disputam a sobreposição do direito e do poder - potestas legibus soluta. Suas lutas ecoam as palavras de Hannah Arendt: "nenhuma revolução jamais teve sucesso [...] enquanto a autoridade do corpo político esteve verdadeiramente intacta" (ARENDT, 1963, p.141).

\section{Referências}

ACKERLY, Brooke; STERN, Maria; TRUE, Jacqui True. Feminist Methodologies for International Relations, Cambridge: Cambridge University Press, 2006. ANAYA, S. James. Indigenous Peoples in International Law. Oxford: Oxford University Press, 2004.

APPADURAI, Arjon. Patriotism and Its Futures. Public Culture, v. 5, n. 3, p. 41129, 1993.

ARCHIBUGI, Daniele; HELD, David Held. Cosmopolitan Democracy: An Agenda for a New World Order. Cambridge: Policy Press, 1995.

ARENDT, Hannah. On Revolution. New York: Viking, 1963. 
BANERJEE, Subhankar (ed.). Arctic Voices: Resistance at Tipping Point. New York: Seven Stories Press, 2012.

BARKER, Joanne. Gender, Sovereignty, and the Discourse of Rights in Native Women's Activism. Meridians, v. 7, n. 1, p. 127-61, 2006.

BEBBINGTON, Anthony; BEBBINGTON, Denise H. An Andean Avatar: PostNeoliberal and Neoliberal Strategies for Securing the Unobtainable. New Political Economy, v. 16, n. 1, p. 131-45, 2011.

BECKER, Marc. Indians and Leftists in the Making of Ecuador's Modern Indigenous Movement, Durham. NC: Duke University Press, 2008.

.Pachakutik: Indigenous Movements and Electoral Politics in Ecuador. Lanham, MA: Rowman and Littlefield Publishers, 2011.

BEIER, J. Marshall. International Relations in Uncommon Places: Indigeneity, Cosmology and the Limits of International Theory. New York: Palgrave Macmillan, 2005.

(ed.). Indigenous Diplomacies. New York: Palgrave Macmillan, 2009.

BELMESSOUS, Saliha (ed.) Native Claims: Indigenous Law Against Empire, 1500-1920, Oxford: Oxford University Press, 2011.

BENHABIB, Seyla. The Claims of Culture: Equality and Diversity in the Global Era. Princeton, NJ: Princeton University Press, 2002.

BRENTON, Lauren. Law and Colonial Cultures: Legal Regimes in World History, 1400-1900.Cambridge: Cambridge University Press, 2001.

.A Search for Sovereignty: Law and Geography in European Empires, 1400 -1900.Cambridge: Cambridge University Press, 2009.

BIOLSI, Thomas. Imagined Geographies: Sovereignty, Indigenous Space, and the American Indian Struggle. American Ethnologist, v. 32, n. 2, p. 239-59, 2005. BRUYNEEL, Kevin. The Third Space of Sovereignty: The Postcolonial Politics of U.S. - Indigenous Relations. Minneapolis, MN: University Of Minnesota Press, 2007.

BUCK-MORSS, Susan. Hegel, Haiti, and Universal History. Pittsburgh, PA: University of Pittsburgh Press, 2009.

CANESSA, Andrew (ed.).Natives Making Nation: Gender, Indigeneity, and the State in the Andes. Tucson, AZ: University of Arizona Press, 2005. 
CHAKRABARTY, Dispesh. Provincializing Europe: Postcolonial Thought and Historical Difference. Princeton, NJ: Princeton University Press, 2000.

Chatterjee, Partha. The Nation and its Fragments: Colonial and Postcolonial Histories. Princeton, NJ: Princeton University Press, 1993.

Empire and Nation: Selected Essays. New York: Columbia University Press, 2010.

COLLOREDO-MANSFIELD, Rudi. Fighting like a Community: Andean Civil Society in an Era of Indian Uprisings. Chicago, IL: University of Chicago Press, 2009.

COMAROFF, John; COMAROFF, Jean. Ethnicity, Inc. Chicago: University of Chicago Press, 2009.

CORNTASSEL, Jeff. Towards a New Partnership? Indigenous Political Mobilization and Co-optation during the First UM Indigenous Decade (19952004). Human Rigths Quartely, v. 29, n. 1, p. 137-66, 2007.

COX, Robert. Social Forces, States and World Orders: Beyond International Relations Theory. In: KEOHANE, Robert O. (ed.). Neorealism and Its Critics. New York: Columbia University Press, pp.204 - 54, 1986.

DEAN, Carolyn. A Culture of Stone: Inka Perpectives on Rock. Durham: Duke University Press, 2010.

DELONA JR., Vine. Conquest Masquerading as Law. In: ARROWA, Four (Don Trent Jacobs) (ed.). Unlearning the Language of Conques: Scholars Expose AntiIndianism in America. Austin, TX: University of Texas Press, 2006.

DELORIA JR., Vine; LYTLE, Clifford M. The Nations Within: The Past and Future of American Indian Sovereignty. Austin, TX: University of Texas Press, 1998.

DEN OUDEN, Amy E. Beyond Conquest: Native Peoples and the Struggle for History in New England. Lincoln, NE: University of Nebraska Press, 2005.

. Colonial Violence and Gendering of Post-War Terrain in Southern New England: Native Women and Rights to Reservation Land in Eighteenth - Century Connecticut. Landscapes of Violence, v. 2, n. 1, Article 3, 2012.

ENGELBERT, Pierre. Africa: Unity, Sovereignty, and Sorrow. Boulder, CO: Lynne Rienner, 2009. 
ENLOE, Cynthia. Masculinity as Foreign Policy Issue. 2005. Disponível em $<$ http://www.fpif.org/reports/masculinity as foreign policy issue $>$. Acessado em 14 de fevereiro de 2013.

ESCÁRCEGA, Sylvia. Authenticating Strategic Essentialism: The Politics of Indigenousness at the United Nations. Cultural Dynamics, v. 22, n. 3, p. 3-28, 2010.

FORD, Lisa. Settler Sovereignty: Jurisdiction and Indigenous Peoples in America and Australia 1788-1836. Cambridge, MA: Harvard University Press, 2010.

GAUDERMAN, Kimberly. Women's Lives in Colonial Quito: Gender, Law, and Economy in Spanish America. Austin, TX: University of Texas Press, 2003.

HABERMAS, Jürgen. The Postcolonial Constellation: Political Essays. Cambridge: Polity Press, 2001.

HENDERSON, Errol A. Hidden in Plain Sight: Racism in International Relations Theory. Cambridge Review of International Affairs, n. 26, v. 2, p. 1-2, 2013.

HOBSON, John M. Is Critical Theory Always for the White West and for Western Imperialism? Beyond Westphalian and Towards a Post-Racist Critical IR. Review of International Studies, v. 33, n. 1, p. 91-116, 2002.

INAYATULLAH, Naeem (ed.).Autobiographical International Relations: I, IR, New York: Routledge, 2011.

JACKSON, Patrick Thaddeus. The Conduct of Inquiry in International Relations: Philosophy of Science and its Implications for the Study of World Politics. London: Routledge, 2011.

KOVACH, Margaret E. Indigenous Methodologies: Characteristics, Conventions, and Contexts. Toronto, ON: University of Toronto Press, 2010.

LIGTHFOOT, Sheryl R. Global Indigenous Politics: A subtle revolution. New York: Routledge, 2016.

MALLON, Florencia E. Decolonizind Native Histories: Collaboration, Knowledge, and Language in the Americas. Durham, NC: Duke University Press, 2011.

MIGDAL, Joel S. Researching the State. In: LICHBACH, Mark Irving; ZUCKERMAN, Alan S. (eds.), Comparative Politics: Rationality, Culture, and Structure. Cambridge: Cambridge University Press, p. 208-36, 2009. 
MORGAN, Rhiannon. Transforming Law and Institution: Indigenous Peoples, the United Nations and Human Rights. Surrey: Ashgate, 2011.

NIEZEN, Ronald. The Origins of Indigenism: Human Rights and the Politics of Identity. Berkeley, CA: University of California Press, 2003.

O'BRIEN, Jean M. Firsting and Lasting: Writing Indians Out of Existence in New England. Minneapolis, MN: University of Minnesota Press, 2010.

OKIN, Susan Moller. Is Multiculturalism Bad for Women's? Princeton, NJ: Princeton University Press, 1999.

PARISI, Laura; CORNTASSEL Jeff. In Pursuit of Self-Determination: Indigenous Women's Challenges to Traditional Diplomatic Spaces. Canadian Foreign Policy Journal, v. 13, n. 3, p. 81-98, 2007.

PICQ, Manuela. Between the Dock and a Hard Place: Hazards and Opportunities of Legal Pluralism for Indigenous Women in Ecuador. Latin American Politics and Society, v. 54, n. 2, p. 1-33, 2012.

SANTOS, Boaventura de Sousa. Las Ultimas Trincheras. 2012. Disponível em:<www.paginas12.com.ar/diario/elmundo/4-202097-2012-08-29.html>. Acessado em 14 de fevereiro de 2013.

SASSEN, Saskia. Territory, Authority, Rights: From Medieval to Global Assemblages. Princeton, NJ: Princeton University Press, 2008.

SCHMITT, Carl. Political Theology: Four Chapter on the Concept of Sovereignty. Chicago, IL: University of Chicago Press, 2006.

SCOTT, James C. The An of Not Being Governed: An Anarchist History of Upland Southeast Asia. New Haven, CT, Yale University Press, 2009.

SETH, Vanita. Europe's Indians: Producing Racial Difference, 1500 1900.Durham, NC: Duke University Press, 2010.

SHADIAN, Jessica. The Politics of Arctic Sovereignty: Oil, Ice and Inuit Governance. New York: Routledge, 2013.

SHAPIRO, Michael J. Moral Geographies and the Ethics of Post-Sovereignty. Public Culture, v. 6, n. 3, p. 479-502, 1994.

SHAW, Karena. Indigeneity and Political Theory: Sovereignty and the Limits of the Political. New York: Routledge, 2008. 
SHILLIAM, Robbie. International Relations and Non-Western Thought: Imperialism, Colonialism and Investigations of Global Modernity. New York: Routledge, 2010.

SIERRA, María Teresa. The Revival of Indigenous Justice in Mexico: Challenges for Human Rights and the States. Political and Legal Anthropology Review, v. 28, n. 1, p. 52-72, 2005.

SMITH, Karen. Contrived Boundaries, Kinship and Ubuntu: A (South) African View of 'the International. In: TICKNER, Arlene B.; e BLANEY, David (eds). Thinking International Relations Differently. London: Routledge, 2012.

SMITH, Linda Tuhiwai. Decolonizing Methodologies: Research and Indigenous Peoples. London, New York, Dunedin, New Zealand: Zed Books and University of Otago Press, 1999.

SONG, Sarah. Justice, Gender, and the Politics of Multicultularism, Cambridge: Cambridge University Press, 2007.

TICKNER, J. Ann. You Just Don't Understand: Troubled Engagements Between Feminist and IR Theorists. International Studies Quarterly, n. 41, v. 4, p. 611-32, 1997.

. Retelling IR's Foundational Stories: Some Feminist and Postcolonial Perspectives. Global Change, Peace, and Security, v. 23, n. 1, p. 5-13, 2010.

TICKNER, Arlene B.; BLANEY, David L. (eds). Thinking International Relations Differently. London: Routledge, 2012.

TROUILLOT, Michel R. Silencing the Past: Power and the Production of History. Boston, MA: Beacon Press, 1995.

VITALIS, Robert. The Noble American Science of Imperial Relations and Its Laws of Rave Development. Comparative Studies in Society and History, v. 52, n. 4, p. 909-38, 2010. 